\title{
Endoscopic Therapy of Biliary Injury After Cholecystectomy
}

\author{
Rainio, Mia
}

2018-02

Rainio , M , Lindström , O , Udd , M , Haapamäki , C , Nordin , A \& Kylänpää , L 2018 , ' Endoscopic Therapy of Biliary Injury After Cholecystectomy ' , Digestive Diseases and Sciences , vol. 63 , no. 2 , pp. 474-480 . https://doi.org/10.1007/s10620-017-4768-7

http://hdl.handle.net/10138/308084

https://doi.org/10.1007/s10620-017-4768-7

publishedVersion

Downloaded from Helda, University of Helsinki institutional repository.

This is an electronic reprint of the original article.

This reprint may differ from the original in pagination and typographic detail.

Please cite the original version. 


\title{
Endoscopic Therapy of Biliary Injury After Cholecystectomy
}

\author{
Mia Rainio ${ }^{1}$ (D) Outi Lindström ${ }^{1} \cdot$ Marianne Udd $^{1} \cdot$ Carola Haapamäki $^{1}$ • \\ Arno Nordin $^{2} \cdot$ Leena Kylänpää ${ }^{1}$
}

Received: 18 May 2017/ Accepted: 16 September 2017/Published online: 25 September 2017

(C) Springer Science+Business Media, LLC 2017

\begin{abstract}
Background Iatrogenic bile duct injury (BDI) is a common complication after cholecystectomy. Patients are mainly treated endoscopically, but the optimal treatment method has remained unclear.

Aims The aim was to analyze endoscopic treatment in BDI after cholecystectomy and to explore endoscopic sphincterotomy (ES), with or without stenting, as the primary treatment for an Amsterdam type A bile leak.

Methods All patients referred to Helsinki University Hospital endoscopy unit due to a suspected BDI between the years 2004 and 2014 were included in this retrospective study. To collect the data, all ERC reports were reviewed. Results Of the 99 BDI patients, 94 (95\%) had bile leak of whom 11 had concomitant stricture. Ninety-three percent of all patients were treated endoscopically. Seventy-one
\end{abstract}

Mia Rainio

mia.rainio@hus.fi

Outi Lindström

outi.indstrom@hus.fi

Marianne Udd

marianne.udd@hus.fi

Carola Haapamäki

carola.haapamaki@hus.fi

Arno Nordin

arno.nordin@hus.fi

Leena Kylänpää

leena.kylanpaa@hus.fi

1 Department of Gastroenterological Surgery, Helsinki University Hospital, Helsinki University, Haartmaninkatu 4, 00290 Helsinki, Finland

2 Department of Transplantation and Liver Surgery, Helsinki University Hospital, Helsinki University, Helsinki, Finland patients had native papillae and a leak in the cystic duct or peripheral radicals. They were treated with ES (ES group, $n=50$ ) or with sphincterotomy and stenting (EST group, $n=21)$. There was no difference between the closure time of the fistula $(p=0.179)$, in the time of discharge from hospital $(p=0.298)$, or in the primary healing rate between the ES group and the EST group (45/50 vs 19/21 patients, $p=0.951$ ).

Conclusion After the right patient selection, the success rate of endoscopic treatment can approach $100 \%$ for Amsterdam type A bile leak. ES is an effective and costeffective single procedure with success rate similar to EST. It may be considered as a first-line therapy for the management of Amsterdam type A leaks.

Keywords Iatrogenic bile duct injury $\cdot$ Endoscopic retrograde cholangiopancreatography $\cdot$ Bile leak · Biliary stent $\cdot$ Sphincterotomy $\cdot$ Amsterdam criteria

\section{Introduction}

Iatrogenic bile duct injury (BDI) is still quite common complication of cholecystectomy. The BDI rate has varied between 0.42 and $1.1 \%$ in earlier studies [1-5]. Bile leak is the most common type of injury, and it can originate at any site in the biliary tree. The cystic duct stump or aberrant biliary duct together with peripheral radicals in the liver is the most common site of the leak [2,3].

The goal in endoscopic retrograde cholangiography (ERC) is to diagnose and treat the injury. Endoscopic therapy in biliary leak is safe and efficacious, and has been reported to be successful in $70-100 \%$ of cases [5-8]. Principle of the treatment of bile leak is to negate the transpapillary pressure gradient to facilitate the flow of bile 
into the duodenum instead of extravasation via the leak. The principal treatment of bile duct stricture, with or without bile leak, is dilatation of bile duct with stents. Although ERC is the treatment method of choice for most BDIs nowadays, the right method used varies. The endoscopic therapy options for BDI are sphincterotomy (ES), stenting with plastic or covered self-expandable metallic stents with or without ES, and nasobiliary drainage.

Several classifications have been developed to describe the severity of BDI and to guide the treatment of injury. One of the most used classifications is the Amsterdam classification, which is quite practical to use for endoscopic purposes (Table 1) [7]. In Amsterdam type A bile duct injuries, the treatment of choice is ES or biliary stenting with or without ES, and percutaneous drainage if needed [7-14]. Type B lesions can also mainly be treated endoscopically, as well as some of the type $\mathrm{C}$ lesions. In more severe type D BDIs, reconstructive surgery is often eventually needed $[7,15]$. Type D lesions can be also treated with a mini-invasive approach by means of endoscopic and radiologic extra-anatomical rendezvous reconstruction $[16,17]$.

Helsinki University Hospital (HUH) is a teaching university hospital serving an area of more than one million inhabitants in South Finland. Laparoscopic cholecystectomies are performed at several hospitals in this area, but the patients are mainly referred to HUH if a BDI is suspected. The aim of this study was to analyze endoscopic treatment of BDI after cholecystectomy at HUH. Special interest was to compare ES, with or without stenting, as the primary treatment method for Amsterdam type A BDI.

\section{Materials and Methods}

To find out the incidence of BDI in Helsinki $(588,000$ inhabitants in 2010), we searched through all the patient records of cholecystectomies for a 2-year period 2010-2011 at HUH. A total of 1667 cholecystectomies were performed, and 18 BDIs were encountered during that time, giving an overall BDI incidence $1.1 \%$. The annual incidence of cholecystectomy in Helsinki was 141 per 100,000 inhabitants. During a 10-year period (2004-2014),

Table 1 Amsterdam classification of severity of bile duct injury

\begin{tabular}{ll}
\hline Type & \\
\hline A & Leak from cystic duct or peripheral radicals \\
B & Major bile duct injury with leak \\
C & Bile duct stricture without leak \\
D & Complete transection or excision of common bile duct
\end{tabular}

120 patients were referred to HUH endoscopic unit due to a suspected BDI. Ninety-nine of these patients demonstrated post-cholecystectomy bile leak or stricture on ERC, and they were included in this study. BDI was confirmed in ERC or in other imaging examinations, such as abdominal computed tomography (CT), abdominal ultrasound (US), and/or magnetic resonance imaging (MRI). All the ERC procedures were performed or supervised by four experienced interventional endoscopists who each perform around 300 ERCPs a year; our total number of ERCPs is more than 1200 per year. To collect the data for this study, all reports about ERC patients were reviewed retrospectively regarding the baseline demographics, the clinical features of the biliary injury, the time between surgery and ERC, the type of ERC management, the presence of biliary stones, the healing and follow-up times, and the adverse events during and after ERC.

The severity of the leak was graded by reviewing the endoscopic images, and it was classified according to the Amsterdam criteria [18]. The leak was graded as "low grade" (LG) if the leak of contrast agent was visible in cholangiography from the distal part of the common bile duct only after opacification of the intrahepatic biliary radicals. A "high-grade" (HG) leak was defined if the leak was seen before intrahepatic opacification [14].

The treatment was determined by the endoscopists based on personal experience and published information at the time of the procedure. The endoscopic therapeutic options were stenting with or without ES or ES alone, bile duct dilatation, or placement of nasobiliary drainage. The technique to do ES was to cut the whole sphincter as far as the duodenal wall, and we confirmed the size of the sphincterotomy with $11.5-\mathrm{mm}$ balloon sweep through the papilla after cutting. If remnant bile duct stones were found, they were also removed.

Primary healing of the leak was defined as the resolution of symptoms or by cessation of drainage in patients with the drain without adverse events. Healing of the strictures was defined when no visible stricture could be seen in the control ERC when the stents were removed, and liver enzymes were at normal level. ERC-related adverse events were classified and graded according to consensus criteria $[19,20]$.

The statistical analyses were performed using SPSS 22.0 (IBM Corporation, Somers, NY) statistical software. The results are given in median and range for continuous variables, and proportions for categorical variables. Comparisons are made between groups using the Chi-square test or Fisher's exact test for categorical variables and a nonparametric Wilcoxon-Mann-Whitney $U$ test for continuous and ordinal variables. 


\section{Results}

The patients' characteristics are outlined in Table 2. Fortyfive percent of the operations were performed due to acute cholecystitis, and the median time of the onset of the symptoms of cholecystitis was 5 days (range 1-60). In $62 \%$ of the operations, intraoperative problems were reported (Table 2). The median time of the beginning of BDI symptoms after cholecystectomy was 2 days (range 0-240). The most common symptoms of BDI were abdominal pain (49\%) and percutaneous bile leak through intraoperatively placed drain (44\%). If there was no drain or no visible bile leak via the drain, diagnosis was made by US (46\%), CT (31\%), and/or MRI (29\%). The usual finding in radiologic examinations was intraabdominal liquid. The median delay from operation to endoscopic treatment was 7 days (range 1-82) in patients with bile leak, and 21 days (range 4-1064) in patients with stricture without leak.

Of the 99 BDI patients, 95 (96\%) had bile leak. Seven patients with leaks had concomitant stricture, and only five patients had stricture without leak. The most common type of injury was cystic duct leak with or without other complications in $61 \%$, followed by $21 \%$ with leak from the duct of Luschka or peripheral biliary radicals. The type of BDI according to Amsterdam classification and endoscopic therapy is shown in Table 3. Endoscopically could be treated $93 \%$ of all the patients. In seven patients (7\%), the ERC procedure remained diagnostic and further surgery was needed due to major BDI for eventual treatment right after the ERC.

There were two cases $(2 \%)$ of post-ERC pancreatitis (mild and moderately severe according to Atlanta classification) but no cases of bleeding, perforation, cholangitis, or mortality related to the endoscopic treatment.

\section{Management of Amsterdam Type A Injuries}

Of the 74 patients with Amsterdam type A injuries, all patients were successfully treated endoscopically. We could identify a group of 71 patients who had native papillae and were treated with ES (ES group, $n=50$ ), or with ES and stenting (EST group, $n=21$ ). Comparison of these two groups reveals that the results are very similar, the primary treatment was equally successful in both of the groups $(p=0.951)$ (Table 4$)$. There was no difference between the closure time of the leak $(p=0.179)$ or the time of discharge from hospital $(p=0.298)$. There was no statistical difference in the primary treatment success between ES group and EST group in the LG leak (32/35 in ES group and 11/12 in EST group; $p=1.000$, Fisher's
Table 2 Characteristics of all the patients $(n=99)$

\begin{tabular}{lc}
\hline Age (years)* & $60(27-93)$ \\
Female & $54(55)$ \\
Type of cholecystectomy & $58(59)$ \\
Laparoscopic & $13(13)$ \\
Open & $28(28)$ \\
Conversion from laparoscopic to open cholecystectomy & $52(53)$ \\
Elective operation & $45(45)$ \\
Acute cholecystitis & \\
Technical problems during surgery reported & $32(32)$ \\
Acute cholecystitis & $17(17)$ \\
Chronic cholecystitis & $5(5)$ \\
Bleeding & $3(3)$ \\
Stone in cystic duct & $3(3)$ \\
Wide cystic duct & $2(2)$ \\
Abscess & \\
Injuries seen intraoperatively & $3(3)$ \\
Bile leak & $5(5)$ \\
Common bile duct injury & $1(1)$ \\
Complete transection of common bile duct & $79(80)$ \\
Biloma drainage after operation & $4(0-52)$ \\
Days of fistula closure* & $5(0-65)$ \\
Hospitalization days after first ERC* &
\end{tabular}

Data are presented as numbers, percentages (\%), and *median (range)

$E R C$ endoscopic retrograde cholangiography 
Table 3 Endoscopic finding and management in all patients
Number of patients (\%)

\begin{tabular}{lc}
\hline Type of duct lesion (Amsterdam classification) & $74(75)$ \\
A & $17(17)$ \\
B & $4(4)$ \\
C & $4(4)$ \\
D & \\
Location of bile leak & $60(64)$ \\
Cystic duct & $21(22)$ \\
Duct of Luschka or peripheral radicals & $13(14)$ \\
Common bile duct & \\
Grade of the leak & $43(46)$ \\
HG & $51(54)$ \\
LG & $17(17)$ \\
Common bile duct stones & \\
Location of biliary stricture & $8(67)$ \\
Common bile duct & $2(17)$ \\
Common hepatic duct & $2(17)$ \\
Right hepatic duct & \\
Endoscopic management & $56(57)$ \\
Endoscopic sphincterotomy & $37(37)$ \\
Endoscopic sphincterotomy and biliary stent & $1(1)$ \\
Biliary stent alone & \\
\hline
\end{tabular}

$H G$ high grade, $L G$ low grade exact test) and the HG leak (13/15 in ES group and 8/9 in EST group; $p=1.000$, Fisher's exact test) subgroups. However, all the patients in the EST group needed a second ERC for stent removal, whereas $90 \%$ of the ES group patients needed just one ERC to be cured. Therefore, there were significantly more ERCs per patient in the EST group than in the ES group [2.1 (mean) compared to 1.2, respectively, $p=0.000]$. Five patients $(10 \%)$ in the ES group needed stenting after the first ERC. We could not find any common factor of these five patients who were not cured after the first ERC and ES. However, all the leaks were ceased at the time of the third ERC and stent removal, except for one patient, who needed nasobiliary drain before the leak was healed. There was no need for surgery in patients of Amsterdam type A lesion. The median followup time for this group was 51 months (range 1-129). One patient died 27 days after ERC; the cause of death was systemic lupus erythematosus and sepsis after a complicated cholecystectomy. There were no other short- or longterm adverse events in this group.

\section{Management of Amsterdam Type B, C, and D Injuries}

Seventeen patients had Amsterdam type B injuries. The site of the leak was in the common bile duct (CBD) in four patients, in the main hepatic duct in five patients, and in the right hepatic duct in one patient. Seven patients had stricture in the CBD with concomitant cystic stump leak. All patients except two of the type $B$ injuries were treated endoscopically with stenting. Three patients (18\%) of Amsterdam type B BDI group needed operative treatment; they had bile leaks from common hepatic duct and right hepatic branch. The final outcome for all these patients was successful.

All four patients with Amsterdam type $\mathrm{C}$ injuries were treated endoscopically without surgery.

All four patients with Amsterdam type D injury were operated on after a diagnostic ERC, and they all underwent Roux-en-Y hepaticojejunostomy. Within the median follow-up time of 37 months (range 12-80 months), there were no late complications in this group. 
Table 4 Comparison of endoscopic sphincterotomy (ES group), and endoscopic sphincterotomy and stenting group (EST group) for Amsterdam type A BDIs

\begin{tabular}{|c|c|c|c|}
\hline & ES group $n=50$ & EST group $n=21$ & $p$ value \\
\hline Female & $27(54)$ & $12(57)$ & $0.808^{\mathrm{a}}$ \\
\hline Age (years)* & $57(27-88)$ & $66(32-93)$ & $0.053^{\mathrm{b}}$ \\
\hline \multicolumn{4}{|l|}{ Type of leak } \\
\hline Cystic stump & $32(64)$ & $16(76)$ & $0.316^{\mathrm{a}}$ \\
\hline Duct of Luschka or peripheral radical & $18(36)$ & $5(24)$ & $0.316^{\mathrm{a}}$ \\
\hline Low-grade leak/high-grade leak & $35 / 15(69 / 31)$ & $12 / 9(57 / 43)$ & $0.296^{\mathrm{a}}$ \\
\hline \multicolumn{4}{|l|}{ Endoscopic treatment } \\
\hline 1. ERC success & $45(90)$ & $19(90)$ & $0.951^{\mathrm{a}}$ \\
\hline \multirow[t]{3}{*}{ 2. ERC number and procedure } & 5 plastic stent & 19 stent removal & \\
\hline & & +1 stone removal and stenting & \\
\hline & & +1 stent change & \\
\hline \multirow[t]{3}{*}{ 3. ERC } & 5 stent removal & 1 stent removal & \\
\hline & +1 nasobiliary stent & 1 diagnostic & \\
\hline & & 1 additional stent & \\
\hline 4. ERC & & 1 stent removal & \\
\hline Total number of ERCs & 60 & 46 & $0.000^{\mathrm{c}}$ \\
\hline Drainage days after ERC* & $4(0-21)$ & $3(1-14)$ & $0.179^{\mathrm{c}}$ \\
\hline Hospitalization days after ERC* & $4(1-53)$ & $4(1-65)$ & $0.298^{\mathrm{c}}$ \\
\hline Stent days* & $40(31-63)$ & $54(29-297)$ & $0.338^{\mathrm{c}}$ \\
\hline Follow-up time, months* & $51(1-129)$ & $28(1-116)$ & $0.028^{\mathrm{c}}$ \\
\hline Post-ERCP pancreatitis & $2(4)$ & $0(0)$ & $0.353^{\mathrm{a}}$ \\
\hline
\end{tabular}

Data are presented as numbers and percentages $(\%)$ of patients or as *median (range)

$B D I$ biliary duct injury

${ }^{\mathrm{a}}$ Chi-square test

${ }^{\mathrm{b}}$ Unpaired independent $t$ test

${ }^{\mathrm{c}}$ Wilcoxon-Mann-Whitney test

\section{Discussion}

When treating Amsterdam type A BDIs, we found that ES alone and ES with stenting had equally good results in biliary leak closure, $90 \%$ success in both groups. Our study does not show whether stenting alone is an efficient treatment since we do sphincterotomies to easier the procedure in nearly all therapeutic ERCs, if there are no higher risks for bleeding. If the position of guide wire in bile duct is lost during the ERCP, the cannulation of the papilla will be easier, quicker, and also safer after sphincterotomy. Despite frequent sphincterotomies, the risk of pancreatitis, bleeding, and perforation has been low in our unit among the native papilla patients including ERPs $(3.8,0.75$, and $0.56 \%$, respectively) [21]. In the present study, there were no perforations in ES or EST groups. Although the role of endoscopic management of BDIs has already been established for decades, it has remained unclear what the optimal endoscopic procedure is, especially when treating these Amsterdam type A BDIs. Of all the patients referred to our unit due to BDI, 93\% could be treated endoscopically. Seven percent were operated on after the diagnostic ERC. The success of endoscopic treatment was $100 \%$ in Amsterdam type A and type C BDI patients. We also managed to treat endoscopically the majority of Amsterdam type B BDIs (82\%), and our success rate was higher than in previous studies [7, 10].

There are many studies showing the effectiveness of endoscopic stenting alone in treatment of biliary leaks after cholecystectomy. Marks et al. [22, 23] have shown in their study with dogs that biliary stenting is superior to ES when treating cystic stump leaks. Kaffes et al. [6] stated that stent insertion alone was superior to ES alone. Dolay et al. [13] concluded in their randomized prospective study of 27 patients that biliary stenting is a more effective method than ES in the management of bile leak on post-cholecystectomy patients without common bile duct dilatation. There are also some studies that show that ES alone could 
be the primary treatment for Amsterdam type A bile duct injuries. Sandha et al. [14] showed in their study of 207 bile leak patients that ES alone is an effective treatment for the LG leaks. For the HG leaks, they still recommended biliary stenting. Aksoz et al. [12] showed in their 31-patient study that ES is an effective treatment ( $87 \%$ success rate) when treating LG biliary leak. They recommend stenting as the primary treatment for HG leaks and for LG leaks only, if treatment with ES fails. In our study, there was no difference in length of hospital stay or time of the fistula closure between the groups; both therapies seem to be equally effective. In our study, we had good results treating Amsterdam type A HG leaks with ES alone with success rate of $87 \%$. If the $\mathrm{ES}$ is the only treatment, it has to be done properly. In our unit, the ES is performed to divide the sphincter completely by extending the incision to the maximum safe limit. Smaller ES may not be effective enough when treating leaks, and this may have been the reason of poorer outcomes in previous studies. There was no need for surgery even if the first endoscopic treatment failed. The ES group needed additional ERCs for $20 \%$ of patients, whereas the ES and stenting group needed additional ERCPs for 24\% of patients after the second (stent removal) ERC. Stents can also be removed with upper endoscopy using either an end- or side-viewing endoscope without performing ERCP, and this could reduce costs and risk effects. However, in our clinic we have the policy that when there is a need for a stent removal, we do perform ERC to get the information if the leak is healed.

Published data support early use of ERC to exclude major biliary injury and to treat the bile leak or stricture endoscopically. The clinical condition of BDI patients may rapidly deteriorate within a few days, if peritonitis, ileus, and sepsis develop. Forty-eight percent of our patients had a drain placed in the primary operation, which made the BDI diagnosis and treatment faster. The median delay for the ERC was 4 days if the drain was placed in the primary operation, and as much as 10 days if the drain was placed radiologically after the initial cholecystectomy. If there is any suspicion of BDI during the cholecystectomy, it is highly recommended to leave a drain to avoid delay.

This is a retrospective study, and we are aware of its limitations. For instance, the exact fistula closure time cannot be determined since no serial repeat cholangiographies were performed. However, we can show here that the accuracy of endoscopic diagnostics is good, and after the correct patient selection, the success rate of endoscopic therapy can approach even $100 \%$. Drain placement is always recommended if there are difficulties with the anatomy of the biliary tree during the operation. We found ES as effective as EST in treating Amsterdam type A BDIs. As an effective and cost-effective single procedure, ES may be considered as the first treatment method in the management of Amsterdam type A BDI.

Funding This study was supported by the Helsinki University Hospital Research Funds, Helsinki, Finland.

Author's contribution MR collected clinical data and performed the data analysis and drafted the manuscript. OL and LK participated in designing and coordinating the study and provided supervision. $\mathrm{CH}$ collected clinical data. MU and AN provided supervision. All authors critically revised the manuscript and read and approved the final version.

\section{Compliance with ethical standards}

Conflict of interest Mia Rainio, Outi Lindström, Marianne Udd, Carola Haapamäki, Arno Nordin, and Leena Kylänpää have no conflict of interest or financial ties to disclose.

\section{References}

1. Nuzzo G, Giuliante F, Giovannini I, et al. Bile duct injury during laparoscopic cholecystectomy: results of an Italian national survey on 56591 cholecystectomies. Arch Surg. 2005;140:986-992. doi:10.1001/archsurg.140.10.986.

2. Veen EJ, Bik M, Janssen-Heijnen ML, De Jongh M, Roukema AJ. Outcome measurement in laparoscopic cholecystectomy by using a prospective complication registry: results of an audit. Int J Qual Health Care. 2008;20:144-151. doi:10.1093/intqhe/mzm073.

3. Karvonen J, Salminen P, Gronroos JM. Bile duct injuries during open and laparoscopic cholecystectomy in the laparoscopic era: alarming trends. Surg Endosc. 2011;25:2906-2910. doi:10.1007/ s00464-011-1641-1.

4. Diamantis T, Tsigris C, Kiriakopoulos A, et al. Bile duct injuries associated with laparoscopic and open cholecystectomy: an 11-year experience in one institute. Surg Today. 2005;35:841-845. doi:10.1007/s00595-005-3038-z.

5. Barkun AN, Rezieg M, Mehta SN, et al. Postcholecystectomy biliary leaks in the laparoscopic era: risk factors, presentation, and management. Gastrointest Endosc. 1997;45:277-282. doi:10. 1016/S0016-5107(97)70270-0.

6. Kaffes AJ, Hourigan L, De Luca N, Byth K, Williams SJ, Bourke MJ. Impact of endoscopic intervention in 100 patients with suspected postcholecystectomy bile leak. Gastrointest Endosc. 2005;61:269-275. doi:10.1016/S0016-5107(04)02468-X.

7. Bergman JJ, van den Brink GR, Rauws EA, et al. Treatment of bile duct lesions after laparoscopic cholecystectomy. Gut. 1996;38:141-147. doi:10.1136/gut.38.1.141.

8. Vitale GC, Tran TC, Davis BR, Vitale M, Vitale D, Larson G. Endoscopic management of postcholecystectomy bile duct strictures. J Am Coll Surg. 2008;206:918-923. doi:10.1016/j.jamcoll surg.2008.01.064. (discussion 924-5).

9. Mavrogiannis C, Liatsos C, Papanikolaou IS, Karagiannis S, Galanis P, Romanos A. Biliary stenting alone versus biliary stenting plus sphincterotomy for the treatment of post-laparoscopic cholecystectomy biliary leaks: a prospective randomized study. Eur J Gastroenterol Hepatol. 2006;18:405-409.

10. Karvonen J, Gullichsen R, Laine S, Salminen P, Gronroos JM. Bile duct injuries during laparoscopic cholecystectomy: primary and long-term results from a single institution. Surg Endosc. 2007;21:1069-1073. doi:10.1007/s00464-007-9316-7.

11. Baillie J. Endoscopic approach to the patient with bile duct injury. Gastrointest Endosc Clin N Am. 2013;23:461-472. doi:10. 1016/j.giec.2013.01.002. 
12. Aksoz K, Unsal B, Yoruk G, et al. Endoscopic sphincterotomy alone in the management of low-grade biliary leaks due to cholecystectomy. Dig Endosc. 2009;21:158-161. doi:10.1111/j. 1443-1661.2009.00878.x.

13. Dolay K, Soylu A, Aygun E. The role of ERCP in the management of bile leakage: endoscopic sphincterotomy versus biliary stenting. J Laparoendosc Adv Surg Tech A. 2010;20:455-459. doi:10.1089/lap.2009.0308.

14. Sandha GS, Bourke MJ, Haber GB, Kortan PP. Endoscopic therapy for bile leak based on a new classification: results in 207 patients. Gastrointest Endosc. 2004;60:567-574. doi:10.1016/ S0016-5107(04)01892-9.

15. Nordin A, Grönroos JM, Mäkisalo H. Treatment of biliary complications after laparoscopic cholecystectomy. Scand J Surg. 2011;100:42-48. doi:10.1177/145749691110000108.

16. Donatelli G, Vergeau BM, Derhy S, et al. Combined endoscopic and radiologic approach for complex bile duct injuries (with video). Gastrointest Endosc. 2014;79:855-864. doi:10.1016/j.gie. 2013.12.034.

17. Fiocca F, Salvatori FM, Fanelli F, et al. Complete transection of the main bile duct: minimally invasive treatment with an endoscopicradiologic rendezvous. Gastrointest Endosc. 2011;74:1393-1398. doi:10.1016/j.gie.2011.07.045.
18. Keulemans YC, Bergman JJ, de Wit LT, et al. Improvement in the management of bile duct injuries? J Am Coll Surg. 1998;187:246-254. doi:10.1016/S1072-7515(98)00155-0.

19. Sarr MG, Banks PA, Bollen TL, et al. The new revised classification of acute pancreatitis 2012. Surg Clin $N$ Am. 2013;93:549-562. doi:10.1016/j.suc.2013.02.012.

20. Cotton PB, Garrow DA, Gallagher J, Romagnuolo J. Risk factors for complications after ERCP: a multivariate analysis of 11,497 procedures over 12 years. Gastrointest Endosc. 2009;70:80-88. doi:10.1016/j.gie.2008.10.039.

21. Rainio M, Lindstrom O, Udd M, Louhimo J, Kylanpaa L. Diclofenac does not reduce the risk of post-endoscopic retrograde cholangiopancreatography pancreatitis in low-risk units. J Gastrointest Surg. 2017;21:1270-1277. doi:10.1007/s11605-0173412-3.

22. Marks JM, Ponsky JL, Shillingstad RB, Singh J. Biliary stenting is more effective than sphincterotomy in the resolution of biliary leaks. Surg Endosc. 1998;12:327-330.

23. Youngelman DF, Marks JM, Ponsky T, Ponsky JL. Comparison of bile duct pressures following sphincterotomy and endobiliary stenting in a canine model. Surg Endosc. 1997;11:126-128. 